\title{
SOSIALISASI PELAKSANAAN SISTEM PENGGUNAAN TRACER SEBAGAI PELACAK BERKAS REKAM MEDIS PADA RUMAH SAKIT NAILI DBS PADANG
}

\section{SOCIALIZATION OF THE USE OF TRACER SYSTEM AS A MEDICAL RECORD FILE TRACKER AT THE NAILI DBS HOSPITAL IN PADANG}

\author{
Yastori* $^{*}$
}

Akademi Perekam Informasi dan Kesehatan (APIKES) IRIS email: yastoriyi@gmail.com

\begin{abstract}
ABSTRAK
Peningkatan mutu layanan kesehatan perlu dilakukan terutama bagi rumah sakit. Rekam medis yang hilang, salah letak, missfile sulit ditemukan dalam waktu yang cepat menjadi permasalahan yang sering terjadi dan mempengaruhi kualitas pelayanan dan menjadi pemicu permasalahan terjadinya berkas rekam medis ganda sehingga mempersulit pengembalian berkas rekam medis sesuai urutan dan mengakibatkan lamanya pelayanan terhadap pasien. Berdasarkan survei pendahuluan, rumah sakit Naili DBS belum menggunakan tracer untuk menandai berkas keluar. Metode yang digunakan adalah observasi dengan wawancara dan diskusi mengenai permasalahan dibagian rekam medis terutama bagian penyimpanan dan pelacakan berkas rekam medis. Pendidikan diberikan melalui sosialisasi pentingnya penggunaan tracer, sistem penggunaan dan tahapan dalam mempersiapkan tracer. Kegiatan ini bertujuan untuk menciptakan budaya pemanfaatan tracer sebagai kartu pelacak berkas rekam medis keluar dari rak penyimpanan berkas, dilaksanakan pada 11 April 2019 dan berjalan lancar. Hasil yang diperoleh yaitu bahwa di rumah sakit Naili DBS belum menggunakan tracer dan cara pelacakan berkas rekam medis dengan melihat nomor rekam medis pada saat pasein melakukan pendaftaran sehingga membutuhkan waktu yang lebih lama jika dibandingkan dengana adanya tracer. Setelah diadakan sosialisasi ini, bagian rekam medis di rumah sakit Naili DBS memahami akan pentingnya tracer pada bagian rekam medis di rumah sakit.
\end{abstract}

Kata kunci : Tracer, Rekam Medis, Missfile

\begin{abstract}
Improving the quality of health services needs to be done especially for hospitals. Missing medical records, misplaced, missfiles are difficult to find in a fast time that is a frequent problem that affects the quality of service and triggers problems with the occurrence of multiple medical record files, making it difficult to return the medical record files in order and result in length of service to patients. Based on preliminary surveys, the Naili DBS hospital has not used tracers to mark outgoing files. The method used is observation with interviews and discussions about problems in the medical records section, especially the storage and tracking of medical record files. Education is given through the socialization of the importance of using tracers, usage systems and stages in preparing tracers. This activity aims to create a culture of utilizing tracers as tracking cards for medical record files off the file storage shelves, held on April 11, 2019 and running smoothly. The results obtained are that the Naili DBS hospital has not used tracer and how to track medical record files by looking at the medical record number at the time of registration so that it takes longer than the tracer. After this socialization, the medical records section at Naili DBS Hospital understood the importance of tracers in the medical record section at the hospital.
\end{abstract}

Keywords: Tracer, Medical Record, Missfile 


\section{PENDAHULUAN}

Salah satu kegiatan yang harus dilaksanakan pada bagian rekam medis yaitu pengelolaan sistem penyimpanan berkas. Menurut [1], pengelolaan penyimpanan berkas rekam medis sangat penting untuk dilakukan dalam suatu institusi pelayanan kesehatan karena dapat mempermudah dan mempercepat ditemukan kembali berkas rekam medis yang disimpan dalam rak penyimpanan, mudah dalam pengambilan dari tempat penyimpanan, mudah pengembaliannya, melindungi berkas rekam medis dari bahaya pencurian, bahaya kerusakan fisik, kimiawi, dan biologi. Untuk menyajikan rekam medis dalam waktu cepat dan tepat maka perlu diminimalisir kesalahan yang dapat memperlambat ketersediaan berkas rekam medis dalam waktu cepat diantaranya yaitu dengan menggunakan tracer.

Beberapa fasilitas di ruang penyimpanan berkas rekam medis diantaranya ada (a) Ruang dengan suhu ideal untuk penyimpanan berkas agar berkas rekam medis tidak lembap, (b) Alat penyimpanan berkas rekam medis, bisa menggunakan Roll o pack, rak terbuka, dan filing cabinet (c) Tracer yang digunakan sebagai pengganti berkas rekam medis di rak filing yang dapat digunakan untuk menelusuri keberadaan rekam medis. Pentingnya tracer sebagai kartu pelacak berkas rekam medis keluar dari rak penyimpanan berkas rekam medis. Dengan adanya penyimpanan berkas rekam medis maka dapat memudahkan ditemukannya kembali berkas rekam medis pasien saat dibutuhkan [1]

Pemanfaatan tracer pada ruang penyimpanan sebenarnya telah tertera didalam aturan pokok yang harus ditaati ditempat penyimpanan menurut [2] adalah sebagai berikut; tidak satu pun rekam medis boleh keluar dari ruang rekam medis, tanpa tanda keluar/kartu peminjaman. Peraturan ini tidak hanya berlaku bagi orang-orang diluar ruang rekam medis, tetapi juga bagi petugas-petugas rekam medis sendiri; seseorang yang menerima/meminjam rekam medis, berkewajiban untuk mengembalikan dalam keadaan baik dan tepat waktunya. Harus dibuat ketentuan berapa lama jangka waktu satu rekam medis diperbolehkan tidak berada dirak penyimpanan. Seharusnya setiap rekam medis kembali lagi ke raknya pada setiap akhir hari kerja, sehingga dalam keadaan darurat staf rumah sakit dapat mencari informasi yang diperlukan; rekam medis tidak dibenarkan diambil dari fasilitas kesehatan, kecuali atas perintah pengadilan.

Berdasarkan wawancara dari survei awal yang dilakukan dengan petugas rekam medis di RS. Naili DBS diketahui bahwa masih terjadi kesalahan letak (missfile) pada berkas rekam medis dan bagian rekam medis di RS. Naili DBS belum 
menggunakan tracer. Hal tersebut dapat membuat semakin lamanya pelayanan terhadap pasien karena adanya penumpukan berkas rekam medis. Oleh karena itu perlu dilakukan sosialisasi tentang pentingnya penggunaan tracer dan tata cara mempersiapkan tracer di rumah sakit pada bagian penyimpanan di RS. Naili DBS

Kegiatan ini bertujuan untuk menciptakan budaya pemanfaatan tracer sebagai kartu pelacak berkas rekam medis keluar dari rak penyimpanan berkas.

\section{METODE PELAKSANAAN KEGIATAN}

Langkah-langkah yang dilakukan dalam kegiatan pengabdian kepada masyarakat yaitu dengan :

1. Observasi ke RS. Naili DBS, melakukan wawancara dan diskusi untuk menghadapi permasalahan dibagian rekam medis terutama pada bagian penyimpanan dan pelacakan berkas rekam medis.

2. Penyuluhan atau sosialisasi tentang pentingnya penggunaan tracer dirumah sakit, sistem penggunaan tracer dan tata cara atau tahapan yang harus dilakukan dalam mempersiapkan dan membuat tracer di rumah sakit kepada bagian rekam medis.

3. Evaluasi tentang pemahaman bagian rekam medis tentang penggunaan tracer tata cara atau tahapan dalam mempersiapkan tracer di rumah sakit dengan menanyakan kembali ke petugas rekam medis tentang materi yang telah diberikan tadi dan diketahui bahwa petugas rekam medis di RS. Naili DBS sudah memahami tentang tracer dan memiliki keinginan untuk membuat tracer di RS. Naili DBS.

\section{HASIL DAN PEMBAHASAN}

Tim Pengabdian Kepada Masyarakat dari Apikes Iris telah melaksanakan kegiatan ini pada 11 April 2019. Metode yang dilakukan yaitu dengan menyampaikan penyuluhan atau sosialisasi mengenai pentingnya penggunaan tracer, sistem penggunaan tracer dan tahapantahapan yang harus dilakukan dalam menyipakan tracer di rumah sakit.

Pada tahapan awal tim PKM mengadakan survei awal dengan wawancara langsung kepada petugas rekam medis yang ada di RS. Naili DBS Padang untuk mengetahui bagaimana penggunaan tracer di RS. Naili DBS Padang. Setelah dilakukan wawancara dan survei diperoleh hasil bahwa terdapat kesalahpahaman pada petugas rekam medis di RS. Naili DBS mengenai tracer yang dapat diketahui ketika tim Pengabdian Kepada Masyarakat Iris menanyakan apakah sudah menggunakan tracer di RS. Naili DBS Padang dan petugas rekam medis menjawab sudah dan memberikan contoh tracer. Setelah dilihat ternyata terdapat kesalahpahaman mengenai apa itu tracer karena yang diberikan oleh petugas rekam 
medis bukan tracer tetapi bukti pasien datang berobat yang didalamnya tertera nomor rekam medis. Akan tetapi setelah dilakukan kegiatan sosialisasi tim Pengabdian Kepada Masyarakat Apikes Iris melakukan evaluasi kepada petugas rekam medis dengan menanyakan pemahaman petugas rekam medis kembali dan diperoleh hasil bahwa petugas rekam medis sudah memahami tracer dan bagaimana tahapantahapan yang harus dilakukan jika ingin membuat tracer di rumah sakit. Sistem penggunaan tracer dan tahapan-tahapan yang harus dilakukan untuk membuat suatu tracer di rumah sakit yaitu memberikan pemahaman dan pengertian kepada petugas rekam medis mengenai pentingnya penggunaan tracer dalam mempermudah dan mempercepat ditemukan kembali berkas rekam medis yang disimpan dalam rak penyimpanan, mudah dalam pengambilan dari tempat penyimpanan, mudah pengembaliannya, melindungi berkas rekam medis dari bahaya pencurian, bahaya kerusakan fisik, mengurangi terjadinya berkas rekam medis ganda karena berkas rekam medis yang dibutuhkan sulit ditemukan sehingga dapat diminimalisir kesalahan yang dapat memperlambat ketersediaan berkas rekam medis dalam waktu cepat (lihat Gambar 1 dan Gambar 2).

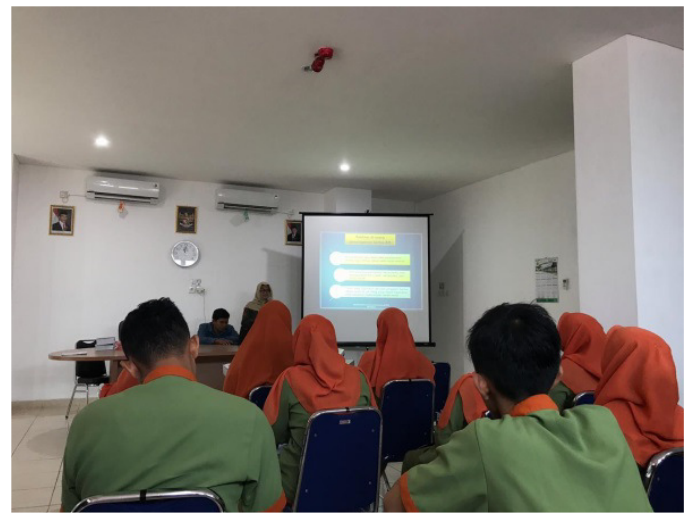

Gambar 1. Sosialisasi Penggunaan Tracer di RS. Naili DBS Padang

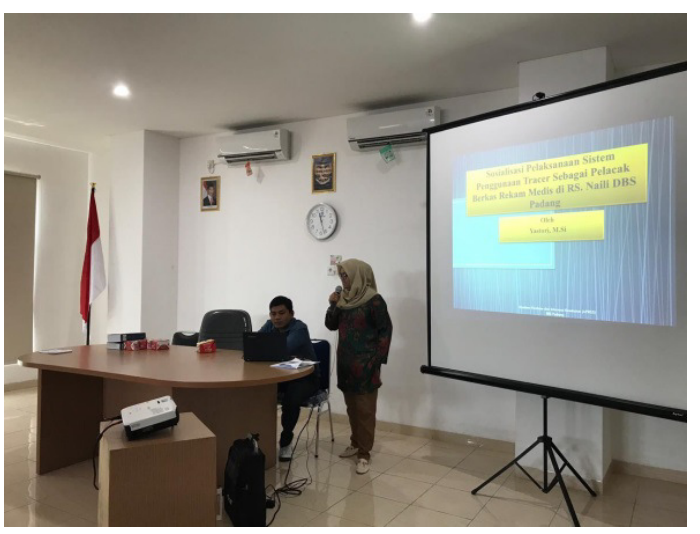

Gambar 2. Penyampaian Materi

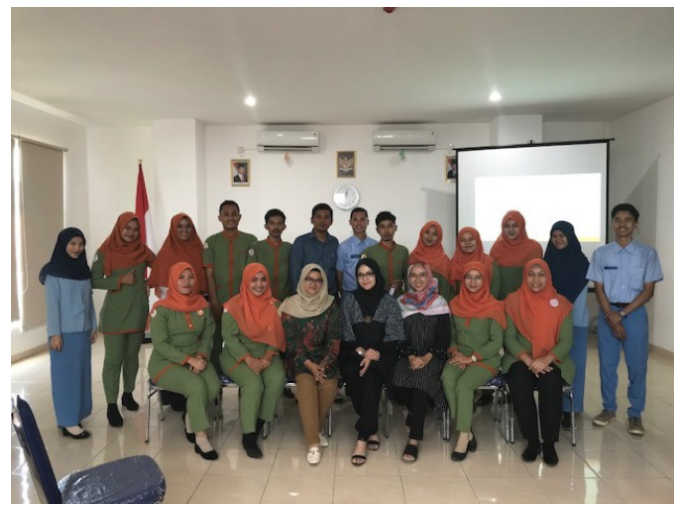

Gambar 3. Foto Bersama Tim Apikes Iris dengan Bagian Rekam Medis RS. Naili

DBS Padang

Evaluasi Program Pengabdian Kepada Masyarakat dilakukan berdasarkan sesi diskusi atau tanya jawab. Pemateri memberikan pertanyaan kepada petugas rekam medis terhadap pertanyaan yang diberikan kepada petugas rekam medis di RS. Naili DBS dan dapat diketahui baha 
petugas rekam medis di RS. Naili DBS

sudah memahami apa itu tracer, apa

kegunaannya dan bagaimana tata cara tahapan-tahapan dalam mebuat tracer.

\section{KESIMPULAN}

Berdasarkan hasil yang diperoleh RS. Naili DBS belum memiliki tracer dan petugas rekam medis belum memahami mengenai tracer. Dengan adanya tracer di suatu rumah sakit dapat mempermudah dan mempercepat ditemukan kembali berkas rekam medis yang disimpan dalam rak penyimpanan, mudah dalam pengambilan dari tempat penyimpanan, mudah pengembaliannya, melindungi berkas rekam medis dari bahaya pencurian, bahaya kerusakan fisik, mengurangi terjadinya berkas rekam medis ganda karena berkas rekam medis yang dibutuhkan sulit ditemukan sehingga dapat diminimalisir kesalahan yang dapat memperlambat ketersediaan berkas rekam medis dalam waktu cepat.

Dalam rangka turut menyumbangkan pemikiran yang berkenaan dengan pentingnya tracer di rumah sakit guna menunjang kualitas rekam medis di rumah sakit maka disarankan sebaiknya untuk rumah sakit memberikan pelatihan kepada petugas rekam medis mengenai design tracer di rumah sakit dan agar segera membuat tracer dikarenakan penting dalam membantu peningkatan kualitas pelayanan di rumah sakit.

\section{UCAPAN TERIMAKASIH}

Kegiatan pengabdian kepada masyarakat ini didanai oleh Hibah Apikes Iris Tahun Anggaran 2019.

\section{DAFTAR PUSTAKA}

[1] Budi, S.C. 2015. Pentingnya Tracer Sebagai Kartu Pelacak Berkas Rekam Medis Keluar Dari Rak Penyimpanan, Indonesian Jurnal of Community Engagement, Volume 1, Halaman 121132.

[2] Depkes RI. 1997. Pedoman Penyelenggaraan Rekam Medis di Rumah Sakit. Jakarta: Dirjen Yanmed.

[3] Huffman, E.K. 1994. Health Information Management. Illinois: Physicians' Record Company.

[4] Miles, M. B dan Huberman, A. M. 1992. Analisis Data Kualitatif (Diterjemahkan oleh Tjetjep Rohendi Rohidi). Jakarta: University of Indonesia Press.

[5] Notoatmodjo, S. 2002. Metode Penelitian Kesehatan. Jakarta: Rineka Cipta. 